\title{
PEMANFAATAN EXCEL UNTUK ANALISIS DAN VISUALISASI DATA KESEHATAN MASYARAKAT KABUPATEN SUKOHARJO
}

\author{
Kiki Ferawati ${ }^{1}$, Muhammad Bayu Nirwana ${ }^{2}$, Hasih Pratiwi ${ }^{3}$, Sri Sulistijowati Handajani ${ }^{4}$, \\ Respatiwulan $^{5}$, Yuliana Susanti', Niswatul Qona'ah ${ }^{7}$ \\ ${ }^{1-7}$ Universitas Sebelas Maret, Surakarta
}

kferawati@staff.uns.ac.id, mbnirwana@staff.uns.ac.id, hasihpratiwi@staff.uns.ac.id,rr_ssh@staff.uns.ac.id, respatiwulan@staff.uns.ac.id, yulianasusanti@staff.uns.ac.id,niswatulqonaah@staff.uns.ac.id

\begin{abstract}
Abstrak
Pemanfaatan data sebagai alat untuk memahami kondisi lingkungan dan kesehatan di wilayah merupakan hal yang harus dikembangkan di era informasi saat ini. Pengetahuan mengenai pengolahan data juga perlu dikembangkan oleh semua kalangan. Sebagai salah satu sekolah negeri yang terletak di Mojolaban, Sukoharjo, guru dan siswa SMPN 1 Mojolaban merupakan bagian dari masyarakat yang memerlukan pengetahuan tentang analisis dan visualisasi data. Profil kesehatan Kabupaten Sukoharjo yang diterbitkan oleh Dinas Kesehatan merupakan salah satu sumber informasi kesehatan yang dari tahun ke tahun dapat diakses oleh publik. Visualisasi data merupakan salah satu metode penyampaian informasi yang dipelajari dalam statistika. Pelatihan Excel yang diberikan bertujuan untuk memberikan pemahaman terkait penerapan metode statistika dengan Excel serta visualisasinya agar masyarakat dapat lebih memahami tentang kondisi kesehatan di wilayah Kabupaten Sukoharjo. Materi yang dibahas meliputi pengorganisasian data, statistik deskriptif, analisis regresi, pivot, pengenalan chart dan pembuatan dasbor. Hasil dari pelatihan yang diberikan, peserta pelatihan mampu membuat dasbor berisikan diagram yang menampilkan kondisi kesehatan dasar di Sukoharjo.
\end{abstract}

Kata Kunci : statistika, kesehatan, visualisasi, Excel, Sukoharjo

PENDAHULUAN

Kabupaten Sukoharjo, Jawa Tengah, merupakan bagian dari Karesidenan Surakarta. Secara geografis, Kabupaten Sukoharjo terletak antara $110^{\circ} 42^{\prime \prime}$ - $110^{\circ} 57^{\prime \prime}$ BT dan $7^{\circ} 32^{\prime \prime}$ - $7^{\circ} 49^{\prime \prime}$ LS, berbatasan langsung dengan Kota Surakarta di bagian utara, Kabupaten Karanganyar di bagian utara dan timur, Kabupten Gunung Kidul dan Wonogiri di bagian selatan, serta Klaten dan Boyolali di bagian barat. Secara administratif, Kabupaten Karanganyar terdiri dari 12 kecamatan (BPS Kabupaten Sukoharjo, 2020).
Pada tahun 2019, jumlah penduduk Kabupaten Sukoharjo adalah 906.403 jiwa, dengan rata-rata kepadatan penduduk 1.942 jiwa/km2. Fasilitas kesehatan yang ada meliputi 12 puskesmas, 10 rumah sakit dan 98 klinik yang tersebar di seluruh wilayah Kabupaten Sukoharjo. Dinas Kesehatan Kabupaten Sukoharjo memiliki misi untuk mewujudkan pelayanan kesehatan paripurna menuju masyarakat yang sehat, sejahtera dan mandiri (Dinas Kesehatan Kabupaten Sukoharjo, 2019). Informasi mengenai kondisi kesehatan masyarakat serta layanan kesehatan yang tersedia merupakan hal yang penting untuk diketahui. 
Layanan kesehatan terdekat di tingkat kecamatan adalah puskemas. Setiap kecamatan di Kabupaten Sukoharjo memiliki Puskesmas masing-masing yang siap untuk melayani seluruh warga sekitar wilayah kerja kecamatan tersebut. Sebuah penelitian untuk memetakan layanan kesehatan di Kabupaten Sukoharjo telah dilakukan dengan hasil sebuah laman web untuk mengetahui informasi tentang kesehatan serta rasio ketersediaan pelayanan kesehatan (Nugrahanto, 2018).

Dasbor Excel merupakan salah satu alat yang dapat digunakan untuk menampilkan berbagai informasi dalam satu tempat yang dapat diakses oleh pengguna. Salah satu keunggulan dasbor adalah fitur interaktif yang dapat berubah sesuai dengan input yang diberikan, sehingga dapat meringkas berbagai macam data dan diagram dalam satu tempat. Di bidang kesehatan, dasbor telah dimanfaatkan untuk menampilkan big data di bidang healthcare menggunakan perangkat lunak $\mathrm{R}$ (Afifah \& Rahmanto, 2020). Akan tetapi, pada praktiknya, penggunaan $\mathrm{R}$ membutuhkan instalasi perangkat baru yang membutuhkan spesifikasi perangkat komputer tertentu agar dapat berjalan dengan maksimal. Selain itu, pengguna $\mathrm{R}$ masih didominasi oleh akademisi, sehingga pengenalan pada masyarakat membutuhkan waktu yang lebih lama. Oleh karena itu, dasbor Excel menjadi pilihan sebagai perangkat lunak yang dilatihkan kepada masyarakat.

Excel merupakan perangkat lunak pengolah angka yang cukup populer karena memiliki fitur yang lengkap. Berbagai macam proses hitung dan pengolahan data bisa dilakukan dengan cepat menggunakan Excel, termasuk membuat diagram dan grafik dalam visualisasi data (Harvey, 2015). Dasbor Excel dapat dibuat dari kombinasi diagram, grafik dan tools yang sudah tersedia. Dasbor dapat membantu pengguna dalam menampilkan data, dari tabel yang sederhana menjadi tampilan yang menarik secara visual dan memiliki makna yang jelas bagi pembaca (Alexander \& Walkenbach, 2013). Banyak pengguna Excel, termasuk siswa dan guru, belum mampu mengoptimalkan penggunaan paket program tersebut. Oleh karena itu, pelatihan Excel ini diharapkan dapat membantu masyarakat, khususnya siswa dan guru, dalam mendapatkan informasi baru mengenai kesehatan wilayah
Sukoharjo menggunakan perangkat yang sudah sering digunakan sehari-hari.

Data kesehatan dapat diakses dari situs Badan Pusat Statistik (BPS) dan Dinas Kesehatan Kabupaten Sukoharjo. Dari data yang tersedia, beberapa variabel yang mempengaruhi tingkat kesehatan di sebuah wilayah antara lain adalah jumlah penduduk dan tingkat kepadatannya, karena berkaitan dengan kondisi lingkungan masyarakat. Dari sebuah penelitian yang dilakukan di Kartasura, Sukoharjo pada tahun 2016, didapatkan bahwa kepadatan pemukiman berpengaruh terhadap wabah kasus Demam Berdarah Dengue (DBD) (Putra, 2018). Kepadatan penduduk juga berpengaruh terhadap kualitas air tanah yang dikonsumsi masyarakat di wilayah tersebut (Fauzi, 2018).

Selanjutnya, beberapa info mengenai tingkat dan fasilitas kesehatan di sebuah wilayah, khususnya dapat diketahui dari kelahiran yang tercatat di wilayah tersebut. Beberapa kejadian bayi lahir mati disebabkan oleh faktor kesehatan janin, penolong persalinan, dan lokasi kelahiran (Putri \& Ningrum, 2019). Oleh karena itu, mengetahui jumlah bayi lahir hidup dan bayi lahir mati di sebuah wilayah dapat menjadi pengetahuan dasar untuk mengetahui kondisi faktor yang mempengaruhi kejadian di wilayah tersebut.

Kondisi kesehatan di sebuah wilayah juga dapat diketahui dari kejadian penyakit menular di wilayah tersebut. Salah satu penyakit yang paling banyak terjadi di masyarakat adalah diare. Kasus diare erat hubungannya dengan kondisi jamban, kondisi saluran pembuangan air, dan kualitas bakteriologis air di wilayah Tegal (Sidhi et al., 2016). Pentingnya mengetahui tentang pencegahan diare sejak dini sudah disadari dan diupayakan oleh banyak pihak, salah satunya adalah penyuluhan penyebab diare dan penyerahan wastafel pada siswa SD di Sukoharjo pada tahun 2019 (Bestari et al., 2021). Pencatatan kasus diare terbagi menjadi kasus balita dan semua umur. Data ini dapat juga digunakan sebagai data awal untuk mengetahui keseluruhan kasus diare yang terjadi di wilayah Kabupaten Sukoharjo.

Kumpulan diagram dari data kesehatan yang ditampilkan dalam dasbor dapat menjadi informasi tambahan bagi masyarakat yang ingin mengetahui kondisi kesehatan umum di wilayah 
Kabupaten Sukoharjo. Dengan mengetahui kondisi kesehatan di wilayah mereka, masyarakat akan dapat menjaga diri sendiri dan keluarganya agar lebih sadar terhadap sebaran penyakit yang berpotensi terjadi di wilayah tersebut. Guru dan siswa di SMPN 1 Mojolaban dapat berperan serta memberikan wawasan dan pengetahuan tentang kesehatan atau bidang lain kepada masyarkat luas apabila dapat mengolah data secara mandiri dengan menggunakan perangkat lunak yang cukup dikenal dan mudah seperti Excel. Oleh karena itu, pelatihan statistika dasar dan visualisasi data menggunakan Excel merupakan hal yang penting untuk diberikan kepada masyarakat.

\section{METODE}

Pelatihan Excel untuk guru dan siswa SMP Negeri 1 Mojolaban dilaksanakan secara daring menggunakan media Zoom. Peserta mengikuti dan mempraktikkan Excel dari perangkat komputer masing-masing. Metode yang digunakan dalam pelatihan ini adalah metode interaktif, diskusi kelas dan langsung menyelesaikan masalah yang disajikan dalam bentuk data kasus kesehatan yang harus diselesaikan dan dianalisis, Selain itu peserta diberikan kesempatan pendampingan apabila ingin belajar dan berkonsultasi dengan memberikan media komunikasi melalui email maupun whatsapps. Pelaksanaan pelatihan terbagi menjadi dua topik utama. Topik pertama adalah data management, meliputi pengorganisasian data, statistik deskriptif, penggunaan Excel tools, dan pivot. Topik kedua adalah visualisasi data, meliputi pengenalan chart di Excel, cara membuat chart, serta kombinasi analisis dan diagram dalam pembuatan dasbor.

Pengorganisasian data meliputi penggunaan

Table, operasi dalam Table, serta summary. Sebelum masuk pembahasan metode, terlebih dahulu dijelaskan tentang skala pengukuran dalam statistika: nominal, ordinal, interval, rasio, dan ukuran yang sesuai untuk setiap skala. Setelah itu, dikenalkan ukuran pemusatan dan penyebaran, serta fungsi yang sesuai untuk mendapatkan ukuran tersebut di Excel. Peserta juga dipandu untuk mengaktifkan dan menggunakan tools Data Analysis di Excel yang memiliki fitur untuk analisis data, antara lain Descriptive Statistics (Statistik deskriptif) dan Regression (Regresi linier sederhana).

Selanjutnya, peserta dipandu untuk mengenali beberapa tipe diagram yang sering digunakan dan memilih diagram yang cocok untuk data yang dimiliki. Dalam sesi ini juga disampaikan beberapa tips tentang cara membuat diagram agar mudah dibaca oleh orang lain. Materi selanjutnya adalah pivot yang mencakup Pivot Table dan Pivot Chart.

Data yang digunakan untuk pembuatan dasbor dalam artikel ini adalah data dari Profil Kesehatan Kabupaten Sukoharjo 2019 yang diterbitkan oleh Dinas Kesehatan Kabupaten Sukoharjo. Variabel yang digunakan adalah kecamatan, jumlah penduduk, luas wilayah, jumlah kelahiran bayi mati dan hidup, jumlah kasus diare balita, dan jumlah kasus diare semua umur.

Langkah pembuatan dasbor data kesehatan dijabarkan sebagai berikut. 1) Membuat rencana elemen dasbor yang akan dibuat. Lima elemen yang akan dibuat adalah diagram batang untuk jumlah penduduk, luas wilayah, kepadatan penduduk, kelahiran bayi, dan kasus diare. 2) Menampilkan diagram batang horizontal untuk jumlah penduduk menggunakan tools Insert $>$ Chart $>$ Bar chart di Excel. Diagram yang dihasilkan kemudian diurutkan berdasarkan jumlah penduduk terbanyak. Hasil ditampilkan di Gambar 1. 3) Menampilkan luas dan kepadatan wilayah setiap kecamatan di Kabupaten Sukoharjo. Luas wilayah total merupakan jumlahan dari seluruh kecamatan yang didapatkan menggunakan fungsi SUM. Kepadatan wilayah merupakan hasil pembagian jumlah penduduk dengan luas wilayahnya, kemudian penentuan kecamatan dengan kepadatan tertinggi dan terendah didapatkan dengan fungsi MAX dan MIN. Hasil ditampilkan di Gambar 2. 4) Membuat list box sebagai alat untuk memilih kecamatan. Pembuatan list box harus mengaktifkan Tab Developer. Hasil ditampilkan di Gambar 3. 5) Membuat diagram lingkaran untuk kelahiran bayi dengan Insert $>$ Chart $>$ Pie chart. Hasil ditampilkan di Gambar 4. 6) Membuat diagram lingkaran untuk kasus diare dengan cara yang sama seperti pada Langkah 5. Hasil ditampilkan di Gambar 5. 7) Menyalin semua elemen dasbor ke sheet baru. 8) 
Mengatur tampilan dasbor, meliputi ukuran dan warna semua elemen dasbor.

Bagian penting dalam pelaksanaan adalah evaluasi hasil pelatihan. Evaluasi diberikan dengan memberikan latihan post test sehingga dapat diketahui berapa persen peserta yang sudah dapat memahami materi dengan baik maupun yang belum. Selain itu diberikan kuisioner yang dapat digunakan untuk evaluasi pengelolaan pelaksanaan pelatihan. Kuisioner tersebut mencakup pendapat peserta mengenai kemanfaatan materi pelatihan, kejelasan dalam menyampaikan materi, fasilitas pendukung seperti modul dan pendampingan konsultasi.serta pengelolaan pelatihan Di akhir kuisioner peserta dapat memberi masukan maupun kritik kepada pengelolaan pelatihan.

\section{HASIL DAN PEMBAHASAN}

Pelatihan Excel dilaksanakan pada tanggal 5-8 Juli 2021, secara luring di SMP Negeri 1 Mojolaban dan secara daring via Zoom meeting. Kegiatan dihadiri oleh guru dan siswa SMP Negeri 1 Mojolaban. Peserta mengikuti pelatihan dengan menggunakan perangkat komputer masing-masing. Materi pelatihan dan data yang digunakan telah diberikan sebelum hari pelaksanaan. Total peserta yang bergabung secara daring mencapai 237 peserta.

Tabel 1. Data penduduk Kabupaten Sukoharjo

\begin{tabular}{lccc}
\hline Kecamatan & $\begin{array}{c}\text { Jumlah } \\
\text { penduduk }\end{array}$ & $\begin{array}{c}\text { Luas wilayah } \\
\left(\mathrm{km}^{2}\right)\end{array}$ & $\begin{array}{c}\text { Kepadatan } \\
\text { penduduk }\end{array}$ \\
\hline Bulu & 38.557 & 43,9 & 879,1 \\
Gatak & 53.321 & 19,5 & 2738,6 \\
Nguter & 56.439 & 54,9 & 1028,4 \\
Tawangsari & 57.207 & 40 & 1430,9 \\
Weru & 58.766 & 42 & 1399,9 \\
Bendosari & 64.282 & 53 & 1213,1 \\
Baki & 70.308 & 22 & 3200,2 \\
Polokarto & 86.300 & 62,2 & 1387,9 \\
Mojolaban & 92.196 & 35,5 & 2594,1 \\
Sukoharjo & 97.305 & 44,6 & 2182,7 \\
Kartasura & 110.548 & 19,2 & 5748,7 \\
Grogol & 121.174 & 30 & 4039,1 \\
\hline
\end{tabular}

Kabupaten Sukoharjo merupakan wilayah yang memiliki fasilitas kesehatan yang cukup lengkap, tersebar di seluruh kecamatan. Salah satu misi dari Dinas Kesehatan Kabupaten Sukoharjo adalah mewujudkan pelayanan kesehatan paripurna menuju masyarakat yang sehat, sejahtera, dan mandiri (Dinas Kesehatan Kabupaten Sukoharjo, 2019). Data jumlah penduduk, luas wilayah dan kepadatan penduduk untuk setiap kecamatan ditunjukkan dalam Tabel 1.

Terdapat 12 kecamatan di wilayah Kabupaten Sukoharjo dengan jumlah penduduk dan luas wilayah yang beragam. Diagram batang dapat digunakan untuk mengetahui banyaknya penduduk di setiap kecamatan. Untuk menunjukkan data tiap kecamatan, diagram batang horizontal lebih sesuai karena nama kecamatan bisa terdiri dari banyak karakter, supaya pengguna dapat lebih mudah dalam membaca diagram. Secara default, diagram ditampilkan menurut urutan data pada tabel yang digunakan untuk membuat chart. Tabel diurutkan dari yang terendah hingga tertinggi, agar tampilan diagram lebih rapi dan mudah dipahami. Diagram yang sudah diurutkan ditampilkan pada Gambar 1.

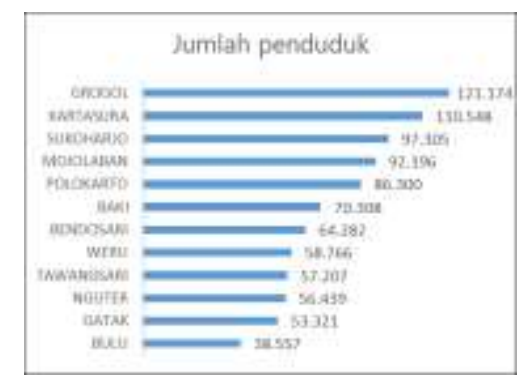

Gambar 1. Diagram batang jumlah penduduk

Berdasarkan Gambar 1, kecamatan dengan jumlah penduduk terbanyak di Kabupaten Sukoharjo adalah Grogol dan kecamatan dengan jumlah penduduk paling sedikit adalah Bulu. Dua kecamatan memiliki penduduk lebih dari serratus ribu jiwa, yaitu Grogol dan Kartasura.

Langkah selanjutnya adalah menampilkan beberapa ringkasan dari data kependudukan Kabupaten Sukoharjo. Ringkasan yang ditampilkan adalah luas wilayah dan kepadatannya. Kepadatan wilayah didapatkan dari jumlah penduduk dibagi dengan luas wilayah per kecamatan yang ditampilkan. Kepadatan wilayah menjadi penting untuk diketahui karena berkaitan dengan kelayakan kondisi lingkungan di wilayah tersebut. Hasil penghitungan ditampilkan di Gambar 2. 


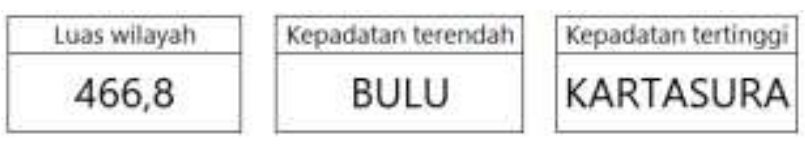

Gambar 2. Luas wilayah dan kepadatan Kabupaten Sukoharjo

Luas wilayah dari seluruh kecamatan yang ada di wilayah Kabupaten Sukoharjo adalah 466,8 $\mathrm{km}^{2}$. Dari diagram pada Gambar 1, daerah dengan penduduk terbanyak adalah Grogol, tetapi jika dilihat dari kepadatannya, kecamatan terpadat adalah Kartasura dengan 5.748 jiwa per $\mathrm{km}^{2}$. Jika dilihat dari luas wilayahnya, Gatak adalah wilayah yang paling kecil, tetapi jumlah penduduknya lebih banyak sehingga Gatak merupakan wilayah terpadat ke-4 di Kabupaten Sukoharjo. Bulu adalah kecamatan dengan kepadatan penduduk terendah.

Sebelum membuat diagram dari data kesehatan, dibuat list box yang akan memudahkan pemilihan kecamatan yang ingin ditampilkan. Hal ini merupakan salah satu keunggulan dasbor, sehingga tidak perlu membuat diagram untuk setiap kecamatan. Diagram yang dibuat dapat berubah sesuai dengan kecamatan yang dipilih dalam list box di Gambar 3. Misalkan pengguna memilih Polokarto, maka diagram lingkaran yang ditampilkan adalah dari data wilayah Polokarto, jika memilih Bulu, yang ditampilkan dari data wilayah Bulu, dan seterusnya.

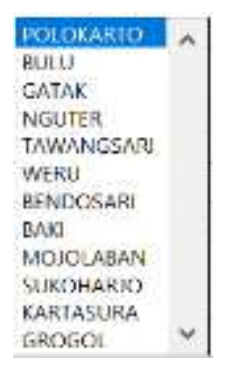

Gambar 3. List box untuk daftar kecamatan di Kabupaten Sukoharjo 2019

Fungsi dari list box ini adalah untuk memilih kecamatan mana yang datanya akan ditampilkan dalam diagram lingkaran untuk data kelahiran dan kasus diare. List box membutuhkan tabel bantuan yang berisi index kecamatan, data kecamatan, kelahiran hidup, dan kelahiran mati. Tabel 2 memuat data kelahiran hidup dan kelahiran mati yang tercatat di wilayah Sukoharjo pada tahun 2019.

Tabel 2. Data kelahiran Kabupaten Sukoharjo

\begin{tabular}{lcc}
\hline Kecamatan & $\begin{array}{c}\text { Kelahiran } \\
\text { hidup }\end{array}$ & $\begin{array}{c}\text { Kelahiran } \\
\text { mati }\end{array}$ \\
\hline Polokarto & 117 & 6 \\
Bulu & 410 & 6 \\
Gatak & 637 & 6 \\
Nguter & 697 & 3 \\
Tawangsari & 715 & 3 \\
Weru & 700 & 7 \\
Bendosari & 840 & 3 \\
Baki & 891 & 1 \\
Mojolaban & 136 & 3 \\
Sukoharjo & 1372 & 3 \\
Kartasura & 1953 & 0 \\
Grogol & 1803 & 3 \\
\hline
\end{tabular}

Jumlah kelahiran mati di setiap kecamatan cukup rendah jika dibandingkan dengan jumlah kelahiran bayi total. Kecamatan dengan kelahiran paling banyak pada 2019 adalah Kartasura dengan 1.952 bayi hidup dan tidak ada bayi lahir mati. Secara keseluruhan, Polokarto cukup mengkawatirkan karena memiliki persentase bayi lahir mati terbesar. Ada 6 bayi lahir mati dan 117 bayi lahir hidup. Persentase bayi lahir mati di Polokarto $4,87 \%$ sehingga perlu diberi perhatian khusus. Contoh diagram untuk kecamatan Tawangsari ditampilkan di Gambar 4. Karena persentase kelahiran bayi mati cukup kecil (sebagian menunjukkan 0\% padahal sebenarnya ada kejadian bayi lahir mati), maka label yang ditampilkan adalah jumlah kelahiran bayinya.

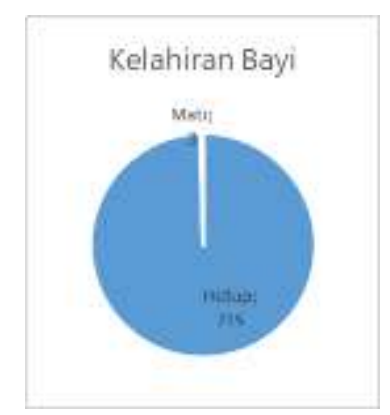

Gambar 4. Diagram lingkaran kelahiran bayi Tawangsari 
Selanjutnya, Tabel 3 memuat data kasus diare yang dilayani di seluruh wilayah Kabupaten Sukoharjo. Dalam pencatatan di dinkes, diare terbagi menjadi semua umur dan kasus balita. Kasus diare pada balita memerlukan perhatian khusus karena memiliki kaitan dengan tingkat kesehatan lingkungan dan gizi bayi di wilayah tersebut, dan balita merupakan rentang usia yang lebih beresiko terkena kasus diare.

Tabel 3. Data kasus diare Kabupaten Sukoharjo

\begin{tabular}{lrrr}
\hline Kecamatan & $>$ 5th & $\begin{array}{c}<5 \text { th } \\
\text { (Balita) }\end{array}$ & $\begin{array}{c}\text { Semua } \\
\text { umur }\end{array}$ \\
\hline Polokarto & 1.147 & 392 & 1.539 \\
Bulu & 290 & 97 & 387 \\
Gatak & 451 & 236 & 687 \\
Nguter & 1.796 & 958 & 2.754 \\
Tawangsari & 650 & 177 & 827 \\
Weru & 1.413 & 288 & 1.701 \\
Bendosari & 497 & 162 & 659 \\
Baki & 761 & 334 & 1.095 \\
Mojolaban & 1.282 & 569 & 1.851 \\
Sukoharjo & 1.570 & 773 & 2.343 \\
Kartasura & 924 & 274 & 1.198 \\
Grogol & 1.378 & 426 & 1.804 \\
\hline
\end{tabular}

Kasus diare pada balita memiliki persentase yang cukup besar dari seluruh kasus diare yang dilayani. Kasus diare yang dilayani untuk semua umur maupun balita terbanyak ada di kecamatan Nguter dengan 2.754 dan 958 kasus. Angka ini berada di atas target penemuan kasus di Nguter, sehingga hal ini menunjukkan bahwa kondisi kesehatan di Nguter perlu mendapatkan perhatian khusus agar tidak terjadi peningkatan lagi. Di kecamatan lain, Tawangsari, yang ditunjukkan pada Gambar 5, terdapat $21 \%$ kasus diare yang terjadi pada balita. Persentase kasus untuk setiap kecamatan bervariasi di angka tersebut dari total kasus semua umur, sehingga pemerintah perlu mengupayakan kembali penyuluhan maupun perbaikan kondisi lingkungan di wilayah tersebut.

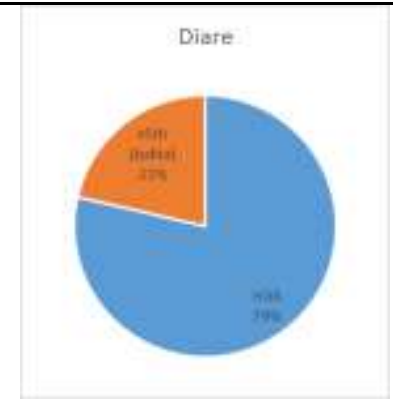

Gambar 5. Diagram lingkaran penderita diare Tawangsari

Setelah semua elemen dasbor siap, maka salin seluruh elemen dasbor ke sheet baru. Peletakan diagram dan sel sebisa mungkin dibuat rapi dan berada dalam bentuk persegi atau persegi panjang agar informasi dalam dasbor mudah dipahami oleh pembaca. Pemilihan warna dalam dasbor juga perlu diperhatikan, supaya semua elemen terlihat seperti satu kesatuan dan saling berhubungan satu sama lain. Contoh dasbor yang dihasilkan dari tahapan pelatihan ditunjukkan oleh Gambar 6.

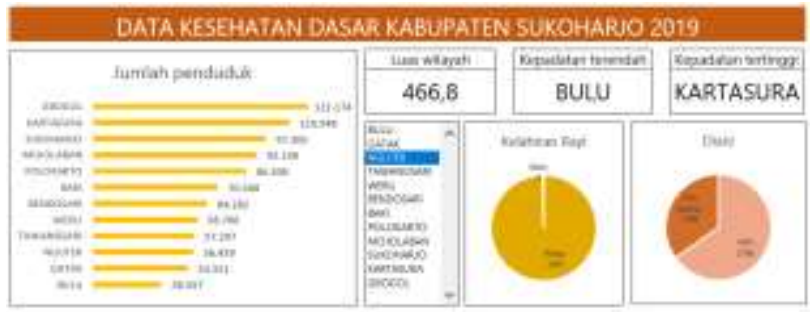

Gambar 6. Dasbor data kesehatan dasar Kabupaten Sukoharjo 2019

Dasbor yang ditunjukkan pada Gambar 6 dapat dimanfaatkan sebagai kumpulan diagram mengenai info tentang kondisi kesehatan di wilayah Kabupaten Sukoharjo, meliputi ringkasan data, diagram batang untuk jumlah penduduk, dan diagram lingkaran untuk kelahiran bayi dan kasus diare. Peserta dapat mengubah tampilan dasbor sesuai preferensi masing-masing, misalnya mengganti atau menambah ringkasan dengan statistik deskriptif yang lain. Selain menggunakan diagram lingkaran, peserta juga boleh mengganti dengan diagram lain yang juga cocok untuk data, misalnya diagram batang. Peserta juga dapat 
mengubah warna sesuai dengan tema yang diinginkan.

Selain itu, jika menggunakan pivot, peserta juga dapat memanfaatkan fitur Slicer atau Timeline sebagai alat memilih data untuk ditampilkan. Peserta juga dapat langsung menyalin diagram dari pivot chart dan menggunakan filter yang sudah tersedia di diagram tersebut. Karena tidak semua data bisa digunakan untuk fitur Slicer dan Timeline, maka peserta perlu memperhatikan struktur data yang dimiliki.

Setelah pelatihan, peserta diberi kuesioner melalui Google Form sebagai evaluasi pelaksanaan kegiatan. Dari seluruh peserta kegiatan, sebanyak 30 orang $(62,5 \%)$ pernah menggunakan paket program Excel untuk keperluan pembelajaran, pengolahan, mengerjakan tugas dan lainnya. Terkait fasilitas pelatihan, sebanyak 41 orang $(85,42 \%)$ menyatakan fasilitas yang diberikan pada pelatihan (file materi, sertifikat, dan lain-lain) sudah memadai. Untuk pemahaman materi, meskipun 45 peserta atau $93,75 \%$ menyatakan penyajian materi pelatihan cukup jelas dan dapat diikuti dengan baik, ternyata masih ada beberapa peserta yang mengalami kesulitan karena sebanyak 32 orang $(66,67 \%)$ masih memiliki kendala dalam melakukan analisis data dan visualisasi. Oleh karena itu, sebagai tindak lanjutnya, meskipun pelatihan telah selesai, tim memfasilitasi semua peserta jika ada yang ingin bertanya terkait materi. Selain itu, hampir semua peserta $(97,92 \%)$ menyatakan bahwa kegiatan pelatihan bermanfaat untuk meningkatkan wawasan mengenai penggunaan Excel bagi guru dan siswa dan berharap agar ada pelatihan lanjutan untuk topik yang lebih lanjut.

\section{KESIMPULAN}

Kegiatan pengabdian dalam bentuk pelatihan Excel untuk siswa dan guru di SMP N 1 Mojolaban berjalan dengan lancar. Guru dan siswa dapat mengikuti pelatihan dengan baik dan materi dapat dipahami serta dipraktikkan oleh para peserta. Hasil akhir dari pelatihan berupa dasbor dapat digunakan untuk menjelaskan kondisi kependudukan dan kesehatan dasar di setiap kecamatan di wilayah Sukoharjo. Di akhir sesi, peserta juga telah menunjukkan contoh penerapan metode yang telah dijelaskan saat sesi materi.

Excel dapat digunakan sebagai salah satu perangkat lunak untuk menampilkan visualisasi data kesehatan di Kabupaten Sukoharjo. Data kesehatan dasar meliputi kelahiran bayi dan kasus diare di wilayah Sukoharjo dapat ditampilkan dalam bentuk dasbor Excel yang bersifat dinamis, yaitu dapat berubah sesuai dengan kecamatan yang terpilih.

\section{UCAPAN TERIMAKASIH}

Ucapan terimakasih disampaikan kepada Universitas Sebelas Maret atas dukungannya melalui Hibah Pengabdian Grup Riset dana Non APBN UNS tahun 2021.

\section{REFERENSI}

Afifah, A., \& Rahmanto, K. N. (2020). Development of the Health Information Analytics Dashboard Using Big Data Analytics. International Proceedings The 2nd ISMoHIM 2020, O(0).

Alexander, M., \& Walkenbach, J. (2013). Excel dashboards and reports (2nd ed.). J. Wiley \& Sons.

Bestari, R. S., Ardilla, N., \& Handayani, S. S. (2021). Penyuluhan Protozoa Usus Penyebab Diare dan Penyerahan Washtafel Pada Siswa SD Makamhaji 03 Sukoharjo. AS-SYIFA: Jurnal Pengabdian Dan Pemberdayaan Kesehatan Masyarakat, 1(2), 115-124.

BPS Kabupaten Sukoharjo. (2020). Kabupaten Sukoharjo Dalam Angka 2020.

Dinas Kesehatan Kabupaten Sukoharjo. (2019). Profil Kesehatan Kabupaten Sukoharjo 2019 .

Fauzi, I. (2018). Pengaruh Kepadatan Penduduk Terhadap Kondisi Kualitas Air Tanah Untuk Keperluan Air Minum Di Kecamatan Kartasura Kabupaten Sukoharjo. Universitas Muhammadiyah Surakarta.

Harvey, G. (2015). Excel 2016 All-in-One for Dummies. (1st ed.). For Dummies [Imprint].

Nugrahanto, D. S. (2018). Pembuatan Sistem Informasi Pelayanan Kesehatan Masyarakat Berbasis Web Mapping (Studi Kasus: Kabupaten Sukoharjo, Provinsi Jawa Tengah). Institut 
Teknologi Nasional Malang.

Putra, B. M. (2018). Analisis Spasial

Penyakit Demam Berdarah Dengue Di Kecamatan

Kartasura Kabupaten Sukoharjo Tahun 2016.

Universitas Muhammadiyah Surakarta.

Putri, S. M., \& Ningrum, W. M. (2019).

Gambaran Penyebab Bayi Lahir Mati (Stillbirth)

pada Proses Persalinan. Journal of Midwifery and

Public Health, 1(1), 37-44.

Sidhi, A. N., Raharjo, M., \& Dewanti, N. A. Y. (2016). Hubungan Kualitas Sanitasi Lingkungan Dan Bakteriologis Air Bersih Terhadap Kejadian Diare Pada Balita Di Wilayah Kerja Puskesmas Adiwerna Kabupaten Tegal. Jurnal Kesehatan Masyarakat (e-Journal), 4(3), 665-676. 